\title{
Mechanical heart valves: Are two leaflets better than one?
}

\author{
YingXing $\mathrm{Wu}, \mathrm{MD}^{\mathrm{a}}$ \\ Rosario Gregorio, $M D^{\mathrm{b}}$ \\ Attilio Renzulli, MD, FECTS ${ }^{\mathrm{c}}$ \\ Francesco Onorati, MD ${ }^{\mathrm{b}}$ \\ Marisa De Feo, $\mathrm{MD}^{\mathrm{b}}$ \\ Gary Grunkemeier, $\mathrm{PhD}^{\mathrm{a}}$ \\ Maurizio Cotrufo, MD, FECTS ${ }^{b}$
}

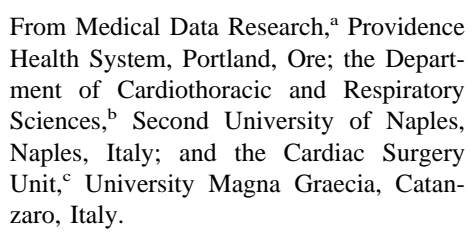

Received for publication May 8, 2003; revisions requested June 16, 2003; accepted for publication Aug 18, 2003.

Address for reprints: YingXing Wu, MD, Medical Data Research, Providence Health System, 9205 SW Barnes Rd \#33LL, Portland, OR 97225 (E-mail: yingxing.wu@ providence.org).

J Thorac Cardiovasc Surg 2004;127:1171-9

$0022-5223 / \$ 30.00$

Copyright $\odot 2004$ by The American Association for Thoracic Surgery

doi:10.1016/j.jtcvs.2003.08.030
Objective: We sought to compare the long-term clinical outcomes of patients who underwent isolated aortic valve replacement with single-disc and bileaflet mechanical heart valves.

Methods: From May 1975 through October 2001, 590 single-disc valves (7 models) were used for isolated valve replacement, and from November 1980 through July 2002, 1283 bileaflet valves (10 models) were used for isolated valve replacement. Detailed follow-up was performed to a maximum of 27.4 and 21.9 years with a total of 6872 and 5811 patient-years for single-disc valves and bileaflet valves, respectively. Survival and valve-related events were analyzed.

Results: Single-disc valves were mainly implanted from 1975 through 1995, whereas bileaflet valves were mainly implanted from 1987 through 2002; thus the years of concurrent use were 1987 through 1995. The bileaflet valve had a significantly lower explantation rate, whereas the single-disc valve had a significantly lower thromboembolism rate. No significant differences were detected in early mortality, long-term survival, and other valve-related complications. When limiting the comparison to the concurrent period of 1987 through 1995, no significant difference was detected in survival or in any valve-related complication.

Conclusion: Single-disc and bileaflet valves provide similar clinical performance. The predominant use of bileaflet valves is not based on clinical outcomes.

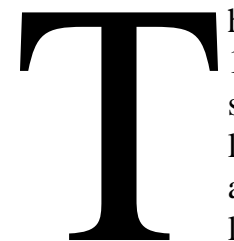

he first successful mechanical heart valves, beginning in the early 1960s, were of the caged-ball design. ${ }^{1}$ Then came the low-profile single-leaflet disc (L1) valves during the $1970 \mathrm{~s},{ }^{2}$ followed by bileaflet (L2) valves since the early 1980s. ${ }^{3}$ L1 valves have a housing with a single free-floating circular disc. L2 valves have 2 semicircular leaflets that are mounted on hinges within a housing that open and close simultaneously. Nowadays, most mechanical valves being implanted are L2 valves. It is generally perceived that, being more "modern," L2 valves must be more advanced. However, the question of which one has better long-term performance remains unanswered.

\section{Materials and Methods \\ Patients}

From May 1975 through October 2001, 590 L1 valves and 1283 L2 valves were implanted in 1873 consecutive patients undergoing isolated aortic valve replacement at the Department of Cardiothoracic and Respiratory Sciences, Second University of Naples, V Monaldi Hospital. There were 7 models of L1 valves and 10 models of L2 valves. These 17 models were divided into 10 subgroups on the basis of similarity of design and manufacturer (Table 1). The choice of prosthesis was according to surgeon preference, and no overt selection criteria were used. The use of valve types over time is shown in Figure 1. L1 valves were 
TABLE 1. Valve groups with 2-letter abbreviations (in parentheses) used to label Figures 4 to 7

\begin{tabular}{lrc}
\hline Valve model (abbreviations) & $\begin{array}{c}\text { No. of } \\
\text { valves }\end{array}$ & $\begin{array}{c}\text { Mean follow-up } \\
\text { (y) }\end{array}$ \\
\hline Single disc (L1) & & \\
$\quad$ Bjork Shiley (BS) & 80 & 12 \\
Medtronic Hall (MH) & 36 & 8 \\
Medical CV (MC) & & \\
$\quad$ Lillehei-Kaster & 6 & 8 \\
$\quad$ Omnicarbon & 8 & 6 \\
Sorin Monodisc (SM) & & \\
$\quad$ Sorin (standard model) & 290 & 13 \\
$\quad$ Sorin Allcarbon & 59 & 9 \\
$\quad$ Sorin Carbocast & 111 & 12 \\
Bileaflet (L2) & 51 & 4 \\
ATS-Medical (AM) & 266 & 3 \\
Edwards MIRA (EM) & 253 & 4 \\
Sorin Bicarbon (SB) & & \\
Carbomedics (CM) & 90 & 8 \\
$\quad$ Carbomedics (standard model) & 202 & 8 \\
$\quad$ Carbomedics HP & & \\
Edwards Lifescience (EL) & 17 & 12 \\
$\quad$ Duromedics & 13 & 4 \\
$\quad$ TEKNA & & \\
St. Jude Medical (SJ) & & \\
$\quad$ St. Jude (standard model) & 335 & 4 \\
$\quad$ St. Jude HP & 52 & \\
St. Jude Regent & 4 & \\
\hline$\quad$ & & \\
\hline & & \\
\hline
\end{tabular}

mainly used from 1975 through 1995, and L2 valves were mainly used from 1987 through 2002, with concurrent use of both types from 1987 through 1995 (Figure 1, shaded area). The percentage use ratio of L1:L2 valves was 97\%:3\% from 1975 through 1986 and 2\%:98\% from 1996 through 2002. From 1987 through 1995, the use ratio was $49 \%: 51 \%$. Because the 2 types of valves were implanted in different eras, many improvements over time could make the results favor the recent valve type. Thus the analyses of the patients operated on from 1987 through 1995, when the 2 types of valve were used concurrently, are considered as the primary analyses, although results are also given for the entire series of valves.

\section{Surgical Technique}

Valve replacement was performed by the same group of surgeons, and the surgical technique remained substantially the same over the years. Standard cardiopulmonary bypass was performed in all cases. Bubble oxygenators were used until January 1990, and since then, hollow-fiber membrane oxygenators were used routinely. Myocardial protection was achieved with mild systemic hypothermia $\left(26^{\circ} \mathrm{C}\right)$, antegrade crystalloid cardioplegia, and topical cooling with the Shumway technique. Kirsh cardioplegia was used until March 1981, and since then, St Thomas 1 solution has been used in all cases. Cardioplegia has been infused through the aortic root in patients with predominant aortic stenosis; in patients with valve regurgitation, cardioplegia was delivered through direct cannulation of the coronary ostia.

All prostheses were inserted in the intra-annular position by using unpledgeted, interrupted, simple Tevdek 2-0 stitches. Single- disc valves were oriented with the main orifice toward the noncoronary sinus and bileaflet valves with their axis perpendicular to the septum. Leaflet mobility was always evaluated at the end of the procedure.

\section{Anticoagulation Methods}

Anticoagulation with warfarin was begun on the second postoperative day for all patients. The criterion for an adequate anticoagulation state was a prothrombin activity of $28 \% \pm 8 \%$, which in our laboratory equals an international normalized ratio of $2.8 \pm$ 0.8 . International normalized ratio assay was performed at least once a month. Data concerning anticoagulation status for each patient were recorded. New hospital admissions either for cardiac or noncardiac causes were recorded as well.

\section{Follow-up}

Our follow-up methodology was about $60 \%$ prospective and $40 \%$ retrospective.

Our collection of follow-up data has high accuracy because our referrals are very restricted, and only a small percentage of patients come to us from other centers. Almost all patients visit our outpatient clinic almost yearly. Nearly $70 \%$ of our population is followed in our anticoagulation clinic by one of us every day. About $20 \%$ of patients are managed in 2 other satellite anticoagulation clinics and followed up by their own physicians, who are well informed and aware of our anticoagulation policy recommendations. Patients who are not followed up at our clinic or by their general practitioner are contacted by telephone or by mail to assess their healthy status. Such work is periodically done by our students doing medical theses. We record any event that occurred since the operation into a dedicated follow-up database. When we decided to begin this project, we initially checked our database, collecting the most recent follow-up data for $56 \%$ of the patients. For patients lost at our follow-up clinic or with their most recent examination more than 6 months old, we checked their status by telephone calls to the patient or his or physician. For patients who did not reply to our telephone call or letter, an official letter was sent to the Polls Department of City Office to assess whether the patient was dead or alive or had moved to another city, and in such cases recontact was made by means of telephone or mail to the latest address. For patients who died during the follow-up period, we interviewed the closest relative.

\section{Statistics}

Data are presented in accordance with the Guidelines for Reporting Morbidity and Mortality After Cardiac Valvular Operations. ${ }^{4}$ Early events, including death, are defined as occurring before hospital discharge or within 30 days after the operation, whichever is longer. Late events were all other events. Comparison between the preoperative characteristics of the 2 valve groups was made by using the $\chi^{2}$ test for discrete variables and the Student $t$ test for continuous variables. Univariate comparison of operative mortality was also made by using the $\chi^{2}$ test. Actuarial survival curves and event-free curves were produced by using the Kaplan-Meier method, with the log-rank test for comparison. Cox regression was used to estimate the effect of risk factors on survival and explantation. Linearized rates, calculated as the number of late events divided by total late follow-up years and then multiplied by 100 to 


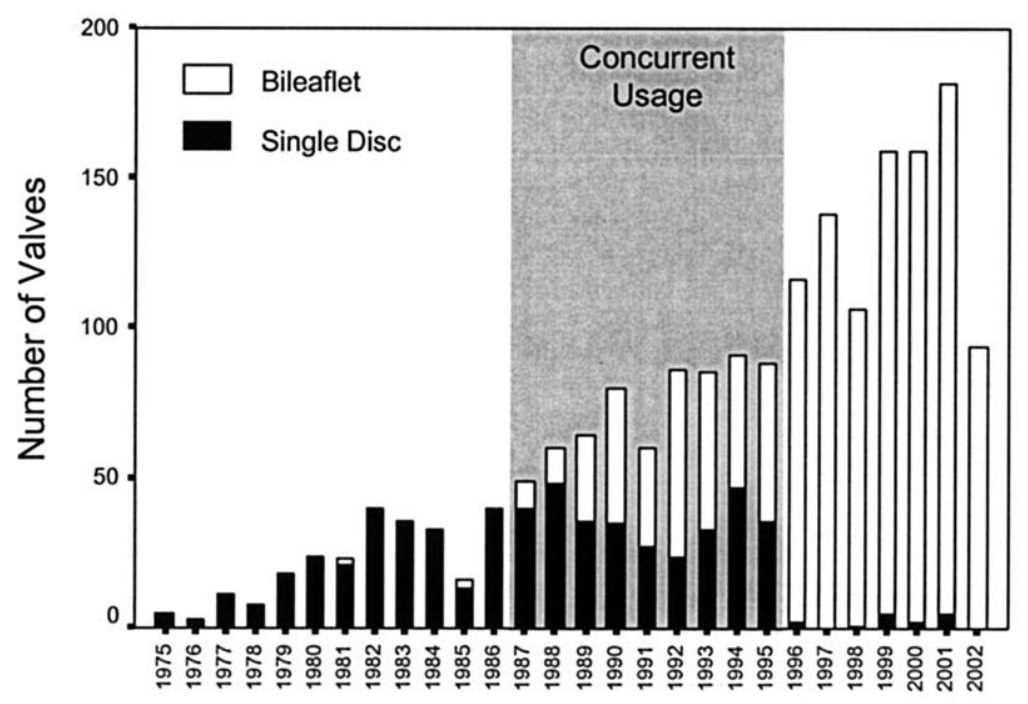

Surgery Year

Figure 1. The use of $L 1$ and $L 2$ valves over time. The shaded area indicates the time period when the use of the 2 valve types overlapped.

TABLE 2. Clinical material for patients undergoing aortic valve replacement by 3 time frames

\begin{tabular}{|c|c|c|c|c|c|}
\hline & \multirow{2}{*}{$\begin{array}{c}1975-1986 \\
\begin{array}{c}\text { Single disc } \\
\text { (L1) }\end{array}\end{array}$} & \multicolumn{3}{|c|}{ 1987-1995 (Concurrent) } & \multirow{2}{*}{$\begin{array}{c}1996-2002 \\
\text { Bileaflet } \\
\text { (L2) }\end{array}$} \\
\hline & & $\begin{array}{l}\text { Single disc } \\
\text { (L1) }\end{array}$ & $\begin{array}{l}\text { Bileaflet } \\
\text { (L2) }\end{array}$ & $P$ value & \\
\hline No. of patients & 249 & 326 & 337 & & 938 \\
\hline Age, y & $44 \pm 13$ & $53 \pm 14$ & $54 \pm 14$ & .9 & $60 \pm 14$ \\
\hline Female sex & $54(22)$ & $71(22)$ & $129(38)$ & $<.001$ & $393(42)$ \\
\hline Valve pathology & & & & .01 & \\
\hline Stenosis & $55(22)$ & $93(29)$ & $126(37)$ & & $482(51)$ \\
\hline Regurgitation & $113(45)$ & $121(37)$ & $99(29)$ & & $257(27)$ \\
\hline Combined & $74(30)$ & $102(31)$ & $92(27)$ & & $181(19)$ \\
\hline Prosthetic dysfunction & $7(3)$ & $10(3)$ & $20(6)$ & & $18(2)$ \\
\hline Valve size $(\mathrm{mm})$ & $23 \pm 2$ & $23 \pm 2$ & $22 \pm 2$ & $<.001$ & $22 \pm 2$ \\
\hline Previous AVR & $7(3)$ & $10(3)$ & $20(6)$ & .08 & $18(2)$ \\
\hline \multicolumn{6}{|l|}{ Follow-up, y } \\
\hline Mean & $15.2 \pm 7.4$ & $9.4 \pm 4.5$ & $8.6 \pm 3.7$ & .02 & $3.0 \pm 2.0$ \\
\hline Maximum & 27.4 & 15.6 & 15.5 & & 6.8 \\
\hline Total & 3777 & 3062 & 2910 & & 2768 \\
\hline Postoperative NYHA class & & & & .6 & \\
\hline I & $126(75)$ & $200(81)$ & $217(83)$ & & $742(88)$ \\
\hline II & $34(20)$ & $40(16)$ & $42(16)$ & & $92(11)$ \\
\hline III & $5(3)$ & $5(2)$ & $3(1)$ & & $5(1)$ \\
\hline IV & $3(2)$ & $1(0)$ & $0(0)$ & & $4(1)$ \\
\hline
\end{tabular}

AVR, Aortic valve replacement; NYHA, New York Heart Association.

convert to the percentage per patient-year, were used to describe late valve-related complications. The $95 \%$ confidence intervals (CIs) for individual linearized rates were calculated with a method suggested by Cox. ${ }^{5}$ The Cochran test ${ }^{6}$ was used to test the heterogeneity of the linearized rates within each group. Because no significant heterogeneity was found among valves of the same type, likelihood ratio tests were used to compare the weighted mean linearized rates between the 2 valve groups. Statistical anal- ysis was done with SPSS10 (SPSS Inc, Chicago, Ill) and S-PLUS 2000 (Insightful Corp, Seattle, Wash) software.

\section{Results}

The patients receiving L1 and L2 implants during the concurrent era had similar clinical profiles (Table 2). Because there were very few cases of L2 valves from 1975 through 


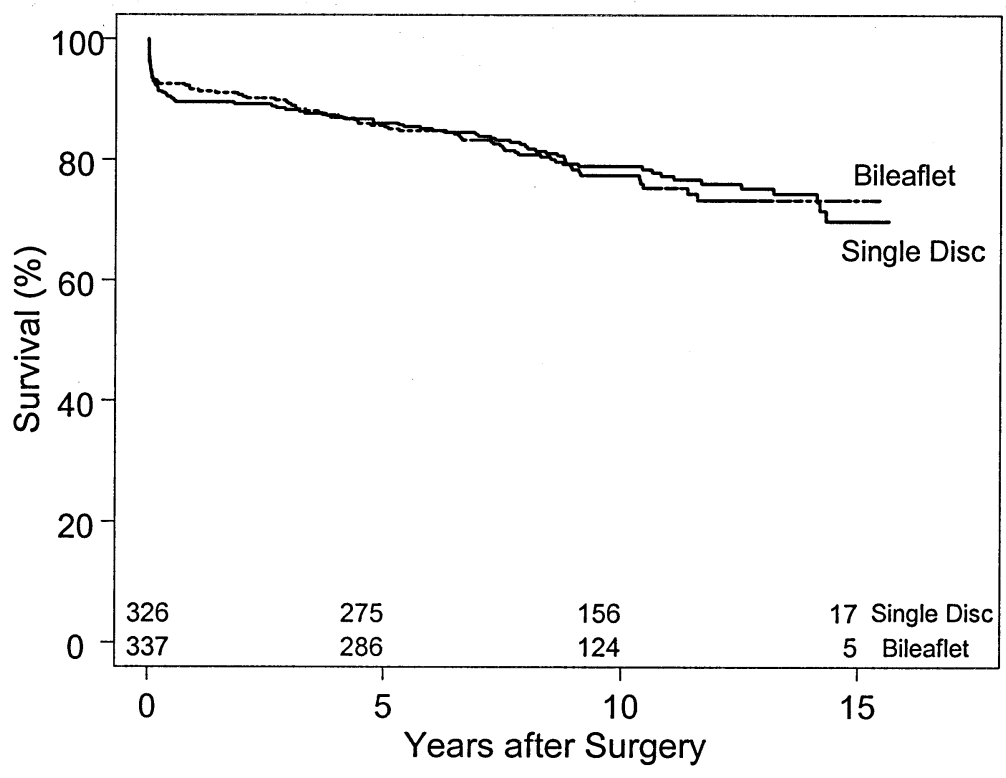

Figure 2. Actuarial overall survival after valve replacement for patients operated on from 1987 through 1995 (shaded area in Figure 1). Numbers above the horizontal axis indicate the number of patients at risk.

TABLE 3. Cause of death: All time frames

\begin{tabular}{|c|c|c|c|c|}
\hline \multirow[b]{2}{*}{ Cause of death } & \multicolumn{2}{|c|}{$\begin{array}{l}\text { Single disc } \\
\text { (L1) }\end{array}$} & \multicolumn{2}{|c|}{$\begin{array}{l}\text { Bileaflet } \\
\text { (L2) }\end{array}$} \\
\hline & Early & Late & Early & Late \\
\hline \multicolumn{5}{|l|}{ Cardiac death } \\
\hline \multicolumn{5}{|l|}{ Valve related } \\
\hline Stroke & - & - & - & 3 \\
\hline Hemorrhage & - & 1 & - & 1 \\
\hline Endocarditis & - & 1 & - & 2 \\
\hline Leak & - & 6 & - & - \\
\hline Fibrous tissue overgrowth & - & 1 & - & 1 \\
\hline Sudden death & - & 20 & - & 13 \\
\hline \multicolumn{5}{|l|}{ Nonvalve related } \\
\hline Acute myocardial infarction & 3 & 11 & 10 & 7 \\
\hline Rupture of aorta, dissection & 2 & 3 & 1 & 1 \\
\hline Arrhythmia & 5 & - & 6 & - \\
\hline Congestive heart failure & - & 9 & 1 & 9 \\
\hline Low output syndrome & 15 & - & 14 & - \\
\hline Mitral valve disease & - & 1 & 一 & - \\
\hline Multiple organ failure & 6 & 2 & 9 & 1 \\
\hline Noncardiac death & 12 & 64 & 30 & 56 \\
\hline Total & 43 & 119 & 71 & 94 \\
\hline
\end{tabular}

1986 and very few cases of L1 valves from 1996 through 2002, these were omitted from Table 2.

\section{Follow-up}

The closing date of this study was October 2002. For the L1 valve group, there were 6872 cumulative patient-years of follow-up, with a mean of 11.6 years and a maximum of 27.4 years. For the L2 valve group, there were 5810 cumu-
TABLE 4. Cause of explantation: All time frames

\begin{tabular}{lcc}
\hline & Single disc (L1) & Bileaflet (L2) \\
\hline Endocarditis & $7(1)$ & $6(2)$ \\
Thrombosis & 2 & \\
Perivalvular leak & $21(5)$ & 4 \\
Fibrous tissue overgrowth & $1(1)$ & $1(1)$ \\
Aortic dissection & $1(1)$ & 1 \\
Ascending aorta aneurysm & $32(8)$ & $12(3)$ \\
Total &
\end{tabular}

Numbers in parentheses indicate fatal explantation.

lative patient-years of follow-up, with a mean of 4.5 years and a maximum of 21.9 years. The follow-up was $100 \%$ complete for both groups. For the concurrent subset of patients from 1987 through 1995, the total follow-up was 3062 patient-years (mean, 9.4; maximum, 15.6) for L1 valves and 2910 patient-years (mean, 8.6; maximum, 15.5) for L2 valves.

\section{Patient Survival}

Early mortality was $7.3 \%$ (43/590) for L1 recipients versus $5.5 \%(71 / 1283)$ for $\mathrm{L} 2$ recipients $(P=.140)$. For the concurrent subset, early mortality was $7.4 \%(24 / 326)$ for L1 recipients versus $6.5 \%(22 / 337)$ for $\mathrm{L} 2$ recipients $(P=$ $.673)$. For the entire series, overall survival was $79 \%$ (95\% CI, $76 \%-82 \%$ ) versus $79 \%$ (95\% CI, $75 \%-83 \%$ ) at 10 years and $68 \%(95 \% \mathrm{CI}, 63 \%-72 \%)$ versus $75 \%$ (95\% CI, $70 \%$ $80 \%)$ at 20 years $(P=.359)$ for $\mathrm{L} 1$ and $\mathrm{L} 2$ valves, respectively. For the concurrent subset, the overall survival was similar between patients receiving $\mathrm{L} 1$ and $\mathrm{L} 2$ valves: $70 \%$ 


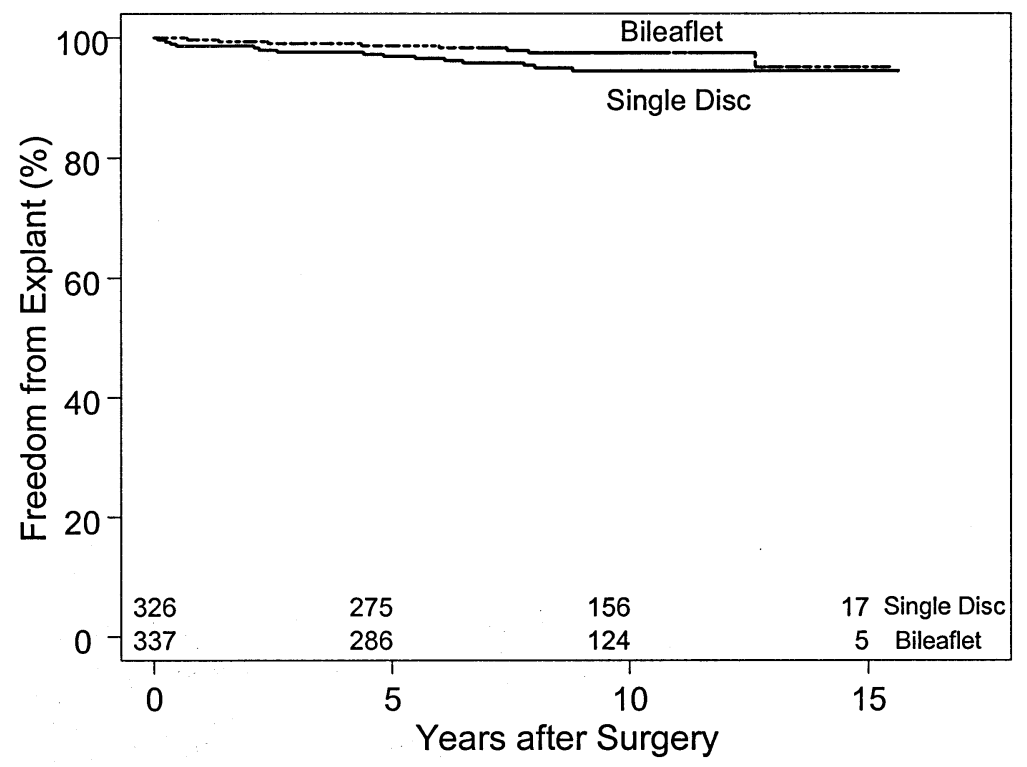

Figure 3. Freedom from explantation after valve replacement for patients operated on from 1987 through 1995 (shaded area in Figure 1). Numbers above the horizontal axis indicate the number of patients at risk.

TABLE 5. Comparisons of linearized event rates within and between valve groups: All time frames

\begin{tabular}{|c|c|c|c|c|c|}
\hline \multirow[b]{2}{*}{ Events } & \multicolumn{2}{|c|}{ Single disc (L1) } & \multicolumn{2}{|c|}{ Bileaflet (L2) } & \multirow{2}{*}{$\begin{array}{c}\text { Likelihood } \\
\text { ratio } \\
P \text { valuet }\end{array}$} \\
\hline & $\begin{array}{l}\text { Linearized rate } \\
\qquad(95 \% \mathrm{CI})\end{array}$ & $\begin{array}{l}\text { Cochran } \\
P \text { value* }\end{array}$ & $\begin{array}{l}\text { Linearized rate } \\
\qquad(95 \% \mathrm{CI})\end{array}$ & $\begin{array}{l}\text { Cochran } \\
P \text { value* }\end{array}$ & \\
\hline Thromboembolism & $0.059(0.020-0.14)$ & .9 & $0.26(0.15-0.42)$ & .7 & .003 \\
\hline Hemorrhage & $0.073(0.028-0.16)$ & .3 & $0.070(0.024-0.17)$ & .2 & .9 \\
\hline Leak & $0.38(0.25-0.55)$ & .7 & $0.28(0.17-0.44)$ & .2 & .3 \\
\hline Endocarditis & $0.16(0.086-0.28)$ & .2 & $0.16(0.078-0.29)$ & .8 & 1 \\
\hline Thrombosis & $0.029(0.0061-0.094)$ & .9 & $0.018(0.0019-0.082)$ & .9 & .7 \\
\hline Explantation & $0.45(0.31-0.64)$ & 6 & $0.21(0.11-0.36)$ & .8 & .02 \\
\hline Death & $1.7(1.5-2.1)$ & .4 & $1.7(1.3-2.0)$ & .1 & .7 \\
\hline
\end{tabular}

$\mathrm{Cl}$, Confidence interval.

${ }^{*}$ Cochran tests of differences within valve models in each group.

tLikelihood ratio tests of differences between valve group.

(95\% CI, 63\%-77\%) versus $73 \%(95 \% \mathrm{CI}, 68 \%-79 \%)$ at 15 years $(P=.758$, Figure 2$)$. In the Cox regression for this subset, age and previous aortic valve replacement were found to be significant risk factors, but valve type was not $(P=.718)$. Causes of death for the entire series are given in Table 3.

\section{Reoperation}

In the entire series $44 \mathrm{~L} 1$ recipients required reoperation: 32 resulted in valve explantation, and 8 were fatal (Table 4). Two thirds of explantations were caused by perivalvular leak. One explantation in this group happened within the 30-day postoperative period. Twenty-one L2 recipients required reoperation: 12 resulted in valve explantation, and 3 were fatal. In the entire series the L2 group had a higher freedom from explantation than the L1 group, with $98 \%$
(95\% CI, 96\%-99\%) versus $95 \%$ (95\% CI, 92\%-96\%) at 10 years and $93 \%$ (95\% CI, 84\%-97\%) versus $91 \%$ (95\% CI, $86 \%-94 \%)$ at 20 years $(P=.012)$. For the concurrent subset of patients, the L2 valve group had a higher, although not significant, result: $95 \%$ (95\% CI, 89\%-98\%) versus $95 \%$ (95\% CI, 91\%-97\%; $P=.146$ ) at 15 years (Figure 3). Cox regression with the concurrent subset found previous aortic valve replacement $(P=.001)$ to be a significant risk factor, but valve type was not $(P=.101)$.

\section{Valve-related Complications}

Death and the valve-related complications of explantation, thromboembolism, hemorrhage, perivalvular leak, endocarditis, and prosthesis valve thrombosis were summarized as linearized rates for the entire series of $4 \mathrm{~L} 1$ subgroups and 6 L2 subgroups (Table 5). The complication rates varied 


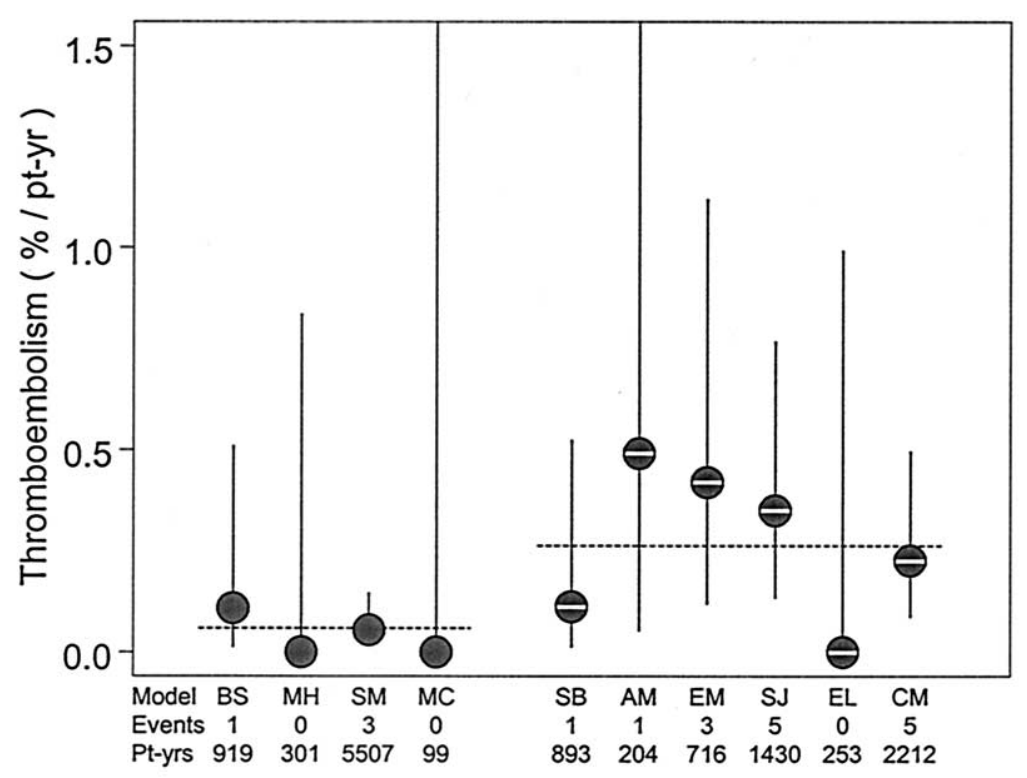

Figure 4. Thromboembolism rates for L1 and L2 valves (all time frames). Circles indicate L1 valves, and paired semicircles indicate $\mathrm{L} 2$ valves. Dashed horizontal lines indicate weighted mean rates for each valve group. Two-letter valve-model abbreviations are specified in Table 1. Numbers at the bottom of the graph show the number of events (Events) and total late follow-up years (Pt-yrs) for each valve model. For statistical comparisons between L1 and L2 valves during the concurrent era only, see Table 6. For model abbreviations, see Table 1.

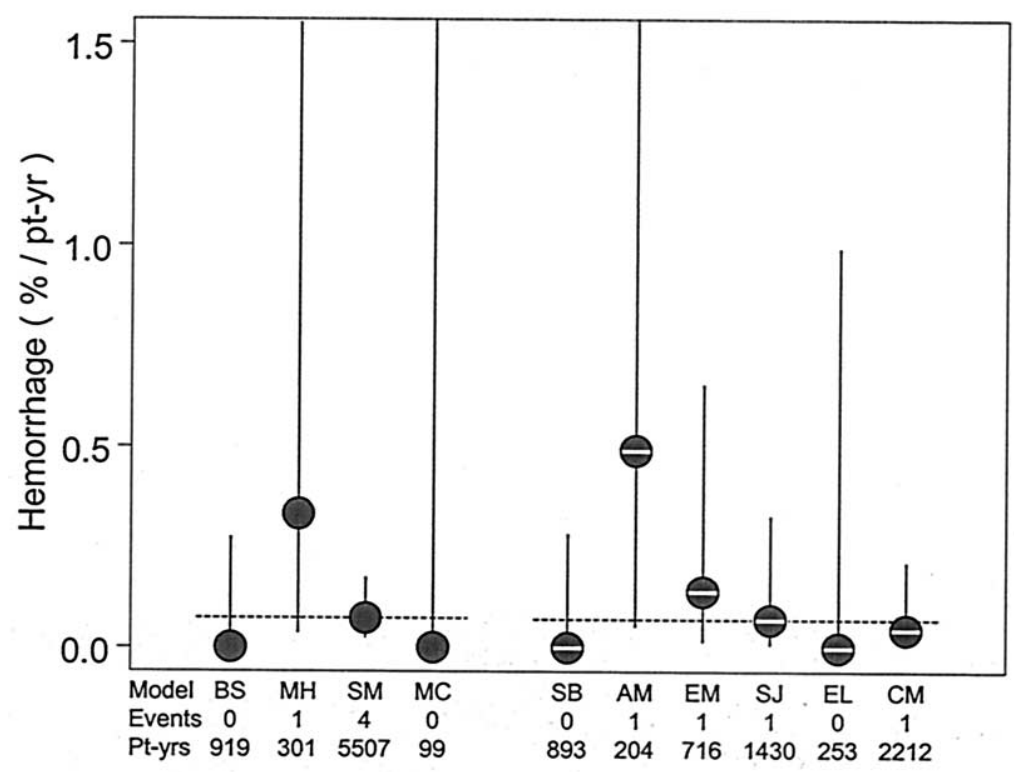

Figure 5. Hemorrhage rates for L1 and L2 valves. See legend to Figure 4.

between and within the L1 and L2 subgroups (Figures 4-7).

To properly compare the pooled complication rates between L1 and L2 valves, we needed to test the assumption that the complication rates of all the subgroups within the same group were homogeneous. ${ }^{7}$ For death and all valverelated complications, the Cochran test did not show signif- icant heterogeneity within either valve group. Therefore weighted mean linearized rates were compared between the L1 and L2 groups (Table 5). The L2 group had a lower explantation rate, whereas the L1 group had a lower thromboembolism rate. The 2 groups had very similar linearized rates for hemorrhage, endocarditis, leak, thrombosis, and 


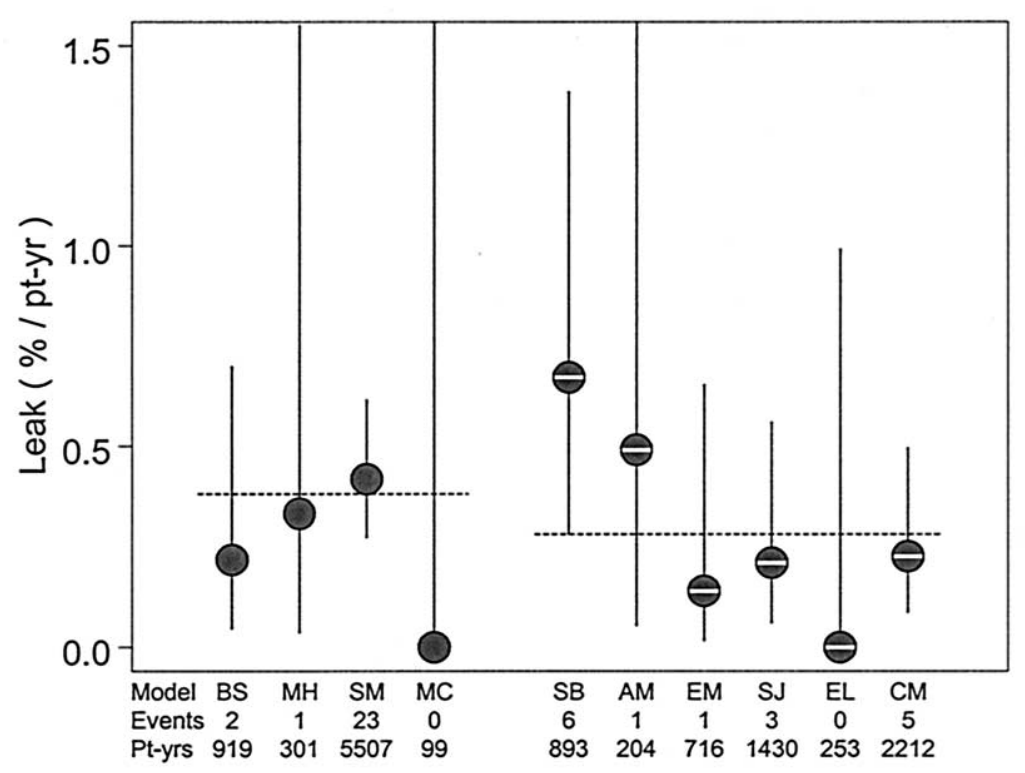

Figure 6. Leak rates for L1 and L2 valves. See legend to Figure 4.

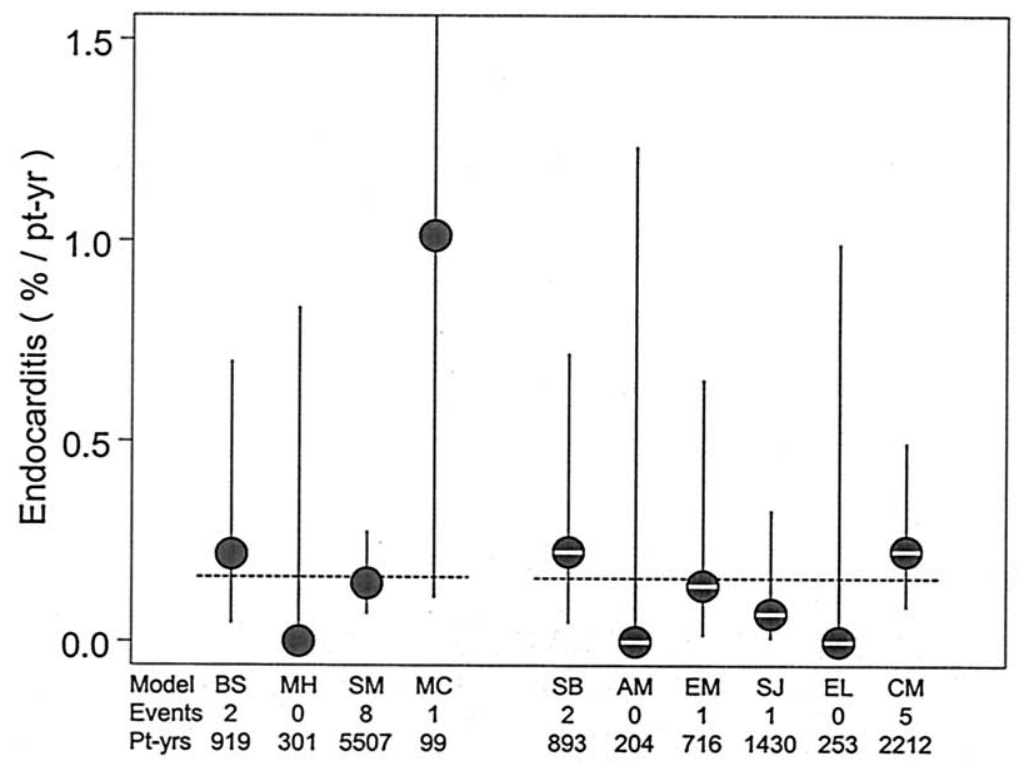

Figure 7. Endocarditis rates for $L 1$ and $L 2$ valves. See legend to Figure 4.

late mortality. Very few valve thromboses were observed in either group.

Separating all the valves by the 3 time periods created 4 well-balanced groups (Table 6). L1 and L2 valves showed consistent complication rates over the different time periods. When the comparison between L1 and L2 is limited to 1987 through 1995, the period of concurrent use, no significant difference was detected for any complications.

\section{Discussion}

There is a common perception that L2 valves, being a later generation of mechanical valves, must be superior to L1 valves with regard to both hemodynamic performance and clinical outcomes. However, some in vitro and in vivo studies have demonstrated that an L1 valve can offer better hemodynamic performance than an L2 valve with both valves implanted in their optimum orientation in the aortic 
TABLE 6. Comparison of the complication rates between valve groups during the 1987 through 1995 period of concurrent use (middle section of table)

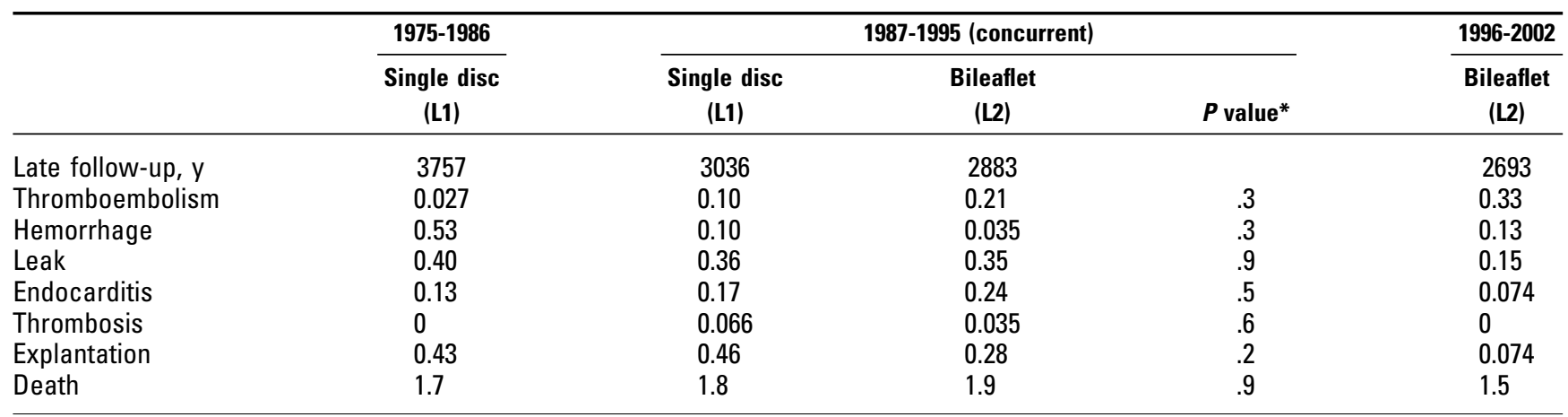

Rates for the remaining valves are given in the outside columns for reference.

* Likelihood ratio tests of differences between valve groups.

position. ${ }^{8-10}$ This is because the $\mathrm{L} 1$ valve's asymmetric design matches the natural eccentric flow profile of the aortic root. However, whether the specific hemodynamic advantages can be translated into better clinical outcome is not clear. The preference for the $\mathrm{L} 2$ valves could also be due to less noise or a perception of more safety as a result of the redundancy of the 2-leaflet design.

Several studies have compared the clinical outcomes of these 2 types of valves on the basis of their experience on 2 or 3 specific valve models. ${ }^{11-14} \mathrm{~A}$ comparison of many published reports found similar event rates between L1 and L2 valves. ${ }^{15}$ In fact, even the earliest caged-ball StarrEdwards valve, for which the design has not been changed since 1966, offers very good performance. ${ }^{16}$ Therefore we summarized our experience of the performance of $590 \mathrm{~L} 1$ valves and $1283 \mathrm{~L} 2$ valves. We hoped this study could provide some information about the long-term performance of these 2 main types of mechanical valves or, if not, to at least open to question the issue of bileaflet valve superiority. Even though we gradually switched from L1 to L2 valves from 1987 through 1995 (Figure 1), looking back now at our 28 years of experience, it seems that this switchover was not evidence based.

There was no significant difference in overall long-term survival for L1 and L2 valves (Figure 3). When the entire series was used, L1 valves had a lower thromboembolism rate but a higher explantation rate, which was primarily because of perivalvular leak. The diagnosis of perivalvular leak was always based on echocardiography. For perivalvular leak, surgeons were more likely to replace the old L1 valve with the newer L2 device but to repair a sterile, leaking L2 valve. When limiting the comparison to the concurrent patients operated on from 1987 through 1995, however, no significant difference was detected in any valve-related complications. The complication rates were low in our study, which could be due to our relatively young patient age; many complications, such as death and thromboembolism, are related to patient age.

The study was a mixture of prospective and retrospective follow-up, and only a limited number of patient characteristics were available for risk adjustment. There are large numbers of valves of both types and long-term follow-up but a small number of valves for some valve models. Moreover, there are few events that could affect the detection of heterogeneity. It is a statistical challenge to compare 2 nonrandomized clinical series. If they are concurrent, there are unknown patient selection factors. If they are consecutive, there are changes over time, which can improve the more recent results. This study included 3 eras: an early one in which L1 valves were used almost exclusively, a recent one in which $\mathrm{L} 2$ valves were used almost exclusively, and a middle one in which both were used concurrently and in almost equal numbers. We were thus able to compare the overall results, which included periods of unselected (almost consecutive) use, and the concurrent results, which matched for time frame of surgical intervention.

The results of the present study show that L1 and L2 valves offer similar good clinical performance. The predominant use of L2 valves has not been scientifically justified on the basis of clinical outcomes.

Three reviewers for the Journal provided thoughtful comments and suggestions and were responsible for several improvements.

\section{References}

1. Starr A, Edwards M. Mitral replacement: clinical experience with a ball valve prosthesis. Ann Surg. 1961;154:726-40.

2. Björk VO. A new tilting disc valve prosthesis. Scand J Thorac Cardiovasc Surg. 1969;3:1-10.

3. Emery RW, Mettler E, Nicoloff DM. A new cardiac prosthesis: the St. Jude Medical cardiac valve: in vivo results. Circulation. 1979;60:4854.

4. Edmunds LH Jr, Clark RE, Cohn LH, Grunkemeier GL, Miller DC, Weisel RD. Guidelines for reporting morbidity and mortality after cardiac valvular operations. Ann Thorac Surg. 1996;62:932-5. 
5. Cox DR. Some simple approximate test for Poisson variates. Biometrika. 1953;40:354-60.

6. Cochran W. Some methods of strengthening the common $\chi^{2}$ tests. Biometrics. 1954;10:417-51.

7. Grunkemeier GL, Wu Y. "Our complication rates are lower than theirs:" statistical critique of heart valve comparisons. J Thorac Cardiovasc Surg. 2003;125:290-300.

8. Kleine P, Scherer M, Abdel-Rahman U, Klesius AA, Ackermann H, Moritz A. Effect of mechanical aortic valve orientation on coronary artery flow: comparison of tilting disc versus bileaflet prostheses in pigs. J Thorac Cardiovasc Surg. 2002;124:925-32.

9. Kleine P, Hasenkam MJ, Nygaard H, Perthel M, Wesemeyer D, Laas J. Tilting disc versus bileaflet aortic valve substitutes: intraoperative and postoperative hemodynamic performance in humans. J Heart Valve Dis. 2000;9:308-12.

10. Kleine P, Perthel M, Nygaard H, Hansen SB, Paulsen PK, Riis C, et al. Medtronic Hall versus St. Jude Medical mechanical aortic valve: downstream turbulences with respect to rotation in pigs. $J$ Heart Valve Dis. 1998;7:548-55.

11. Masters RG, Helou J, Pipe AL, Keon WJ. Comparative clinical out- comes with St. Jude Medical, Medtronic Hall and CarboMedics mechanical heart valves. J Heart Valve Dis. 2001;10:403-9.

12. Antunes MJ. Clinical performance of St. Jude and Medtronic-Hall prostheses: a randomized comparative study. Ann Thorac Surg. 1990; 50:743-7.

13. de la Fuente A, Sanchez R, Romero J, Berjon J, Imizcoz MA, Fernandez JL, et al. CarboMedics and Monostrut valves: clinical and hemodynamic outcomes in a randomized study. $J$ Heart Valve Dis. 2000;9:303-7.

14. Vogt S, Hoffmann A, Roth J, Dubach P, Bertschmann W, Hasse J, et al. Heart valve replacement with the Bjork-Shiley and St Jude Medical prostheses: a randomized comparison in 178 patients. Eur Heart J. 1990;11:583-91.

15. Grunkemeier GL, Li HH, Naftel DC, Starr A, Rahimtoola SH. Longterm performance of heart valve prostheses. Curr Probl Cardiol. 2000;25:73-154

16. Godje OL, Fischlein T, Adelhard K, Nollert G, Klinner W, Reichart B. Thirty-year results of Starr-Edwards prostheses in the aortic and mitral position. Ann Thorac Surg. 1997;63:613-9. 